\title{
Charles-Joseph De Ligne, Caractères et portraits
}

\section{Maria Immacolata Spagna}

\section{(2) OpenEdition}

\section{Journals}

\section{Edizione digitale}

URL: http://journals.openedition.org/studifrancesi/36238

DOI: 10.4000/studifrancesi.36238

ISSN: 2427-5856

\section{Editore}

Rosenberg \& Sellier

\section{Edizione cartacea}

Data di pubblicazione: 1 juillet 2005

Paginazione: 171-172

ISSN: 0039-2944

\section{Notizia bibliografica digitale}

Maria Immacolata Spagna, «Charles-Joseph De Ligne, Caractères et portraits», Studi Francesi [Online], 145 (XLIX | I) | 2005, online dal 30 novembre 2015, consultato il 18 avril 2021. URL: http:// journals.openedition.org/studifrancesi/36238 ; DOI: https://doi.org/10.4000/studifrancesi.36238

\section{Questo documento è stato generato automaticamente il 18 avril 2021.}

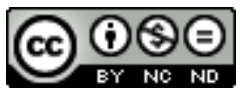

Studi Francesi è distribuita con Licenza Creative Commons Attribuzione - Non commerciale - Non opere derivate 4.0 Internazionale. 


\title{
Charles-Joseph De Ligne, Caractères et portraits
}

\author{
Maria Immacolata Spagna
}

\section{NOTIZIA}

CHARLES-JOSEPH DE LIGNE, Caractères et portraits, Édition critique dirigée par DANIELLE ACKE avec la collaboration de Raymond TROUSSON, Jeroom VERCRUYSSE et Helmut WATZLAWICK, Paris, Honoré Champion, 2003, («L'Âge des Lumières», n. 24), pp. 615.

1 La presente edizione critica offre un excursus dei «caractères» e dei «portraits» tratteggiati dal principe de Ligne. Il volume si articola in più parti. La prima sezione, quella dei «Textes autobiographiques», raggruppa quattro testi apparsi per la prima volta nei Mélanges militaires, littéraires et sentimentaires, tra il 1796 e il 1807: De moi pendant le jour. De moi pendant la nuit, Mémoire pour mon coeur accusé, Mes adieux à Beloeil e Voyage pittoresque à côté de ma chambre in cui dominano gli elementi autobiografici insieme alle osservazioni e riflessioni di un moralista della portata di de Ligne. Anche in Règne du Grand Selrahcengil, pubblicato nel 1801 nei Mélanges militaires, littéraires et sentimentaires, sono chiari gli accenti autobiografici pur celati nel racconto utopistico. È facile riconoscere nella narrazione le tracce di Beloeil, dimora preferita e tanto amata da de Ligne, ricreata con l'immaginazione.

2 La sezione più ampia della presente edizione critica è quella dedicata ai "Portraits et caractères". I curatori del volume ne raccolgono tutti i testi compresi i manoscritti, rimasti fino a questo momento inediti a causa dei contenuti talvolta scandalosi. Vengono presentati dapprima i "portraits" e i "caractères" contenuti nei Mélanges, supervisionati dallo stesso de Ligne; quelli dell'antologia di Mme de Staël realizzati in stretta collaborazione con lui; quelli, infme, raccolti nell'edizione Malte-Brun, pubblicati senza il suo consenso. La seconda parte della sezione racchiude i manoscritti Galerie de portraits e due gruppi della mano di Marie-Christine de Ligne, figlia del principe. Seguono due altre serie di ritratti di sovrani e sovrane, alcune note su 
contemporanei di de Ligne, i ritratti del maresciallo Lacy, quelli di Chateaubriand, altri conservati nell'archivio di Decin e un'ultima parte dal titolo "Divers portraits et caractères posthumes". Accanto ad alcuni autoritratti, il principe ritrae alcuni membri della sua famiglia (i suoi figli, ad esempio), sovrani come l'imperatore Joseph II, la Regina Marie-Caroline d'Austria, Louis XV di Francia, la zarina Catherine II, conti e duchi che ha avuto modo di conoscere e frequentare, amici come il cavaliere di Saxe, scrittori come Chateaubriand e Mme de Stael, servendosi spesso di nomi fittizi. De Ligne si abbandona anche alla descrizione di "caractères" in cui esplora particolari comportamenti tipici del libertino, dello sciocco, del malinconico, usando questi testi per una critica dei vizi sociali.

3 Seguono i reportages degli incontri del principe con Voltaire e Rousseau. Sono riportate, di seguito, la versione pubblicata nel 1796 nei Mélanges, dal titolo Mes conversations avec M. de Voltaire e l'altra, riscritta e ampliata, pubblicata nell'antologia curata da Mme de Staël Lettres et pensées du maréchal prince de Ligne, nel 1809, intitolata Mon séjour chez M. de Voltaire; la versione apparsa nel 1796 nei Mélanges dal titolo Mes conversations avec Jean-Jacques e quella dell'antologia di Mme de Staël del 1809 con il titolo leggermente modificato Mes deux conversations avec Jean-Jacques. Il volume si conclude con il racconto biografico dedicato a Casanova, amico e fedele compagno di de Ligne, in cui delinea il ritratto di un vecchio triste e solitario, nostalgico delle sue avventure passate, ingrato verso i suoi benefattori, sofferente di manie di persecuzione, incapace di accettare le difficoltà fisiche dovute all'età.

4 Una produzione così varia e di tali proporzioni fa sicuramente del principe uno dei ritrattisti più prolifici del suo tempo. Il presente volume costituisce un prezioso contributo per una più profonda conoscenza di de Ligne e dei suoi contemporanei. 